\title{
Effects of Multimedia Instructional Message on Motivation and Academic Performance of Elementary School Students in Croatia
}

\author{
Tomislava Lauc
}

Faculty of Humanities and Social Sciences, University of Zagreb, Croatia, tlauc@ffzg.hr

Gordana Kuterovac Jagodić

Prof., Faculty of Humanities and Social Sciences, University of Zagreb, Croatia, gkuterovac@ffzg.hr

\section{Jelena Bistrović}

Elementary school "Braca Radic”, Koprivnica, Croatia, jelena.suric@skole.hr

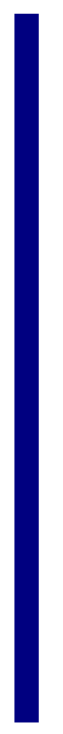
The study examined motivation and learning outcomes of the use of multimedia instructional message during the introductory part of 18 lessons of school subject Nature and Society in 4th grade. Learning outcomes were measured by immediate knowledge tests and global exams. The multimedia model was developed containing activities used either through multimedia presentations, or in a traditional manner, such as using printed text and picture. Multimedia presentations, created according to the multimedia learning principles, represented multimedia instructional and motivational messages. They consisted of six groups of activities: association games, videos, interactive stories, interactive maps, visual stimuli, and crossword puzzles and quizzes. Field quasi-experiment was conducted with the experimental group exposed to instructional and motivational message on computer, and the control groups exposed to the message by traditional teaching aids. The participants were 170 pupils from four Croatian schools. The experimental group consisted of 97 and the control group of 73 students. Using multimedia instructional messages gave better learning outcomes, measured by immediate knowledge tests, while the effect was partially visible in the more global exams. The experimental group rated the activities more fun, interesting and instructional than the control group. The higher motivation was positively correlated to better learning outcomes.

Keywords: instructional design, motivation, multimedia instructional message, elementary school students 


\section{INTRODUCTION}

Students often lack motivation for learning, especially if they come across instructional content that is weakly related to their needs and interests. Thus, the introductory part of every lesson should be motivational. In order to raise students' interest and curiosity in learning, teachers use different approaches in the introductory part of a lesson. One of the approaches may include asking children to recall previous experience and knowledge to connect it to the new content of learning. This recollection can be done by the mean of traditional learning and teaching aids, such as printed text and pictures (e.g. the printed posters, photographs, and maps).as well as through multimedia and computer. Explaining the difference between sensory and cognitive curiosity, Malone and Lepper (1987) stated that sensory curiosity is stimulated by sensory stimulations of the teaching environment such as sound, image, colours or movement, and in educational computer programs it can be enhanced by manipulating digital elements and interactivity. Evoking cognitive curiosity is related to the possibility of altering higher cognitive structures. The authors state that humans have a cognitive urge to shape their cognitive structures. Thus, the learning environments can stimulate curiosity and be motivating for students. The ARCS model (Attention / Relevance / Confidence / Satisfaction) was developed to understand the main effects of motivation on learning (Keller, 1987).

Besides attention focused on learning, which can be stirred by stimulating interest and curiosity, the model highlights the relevance of learning content, confidence in success, and satisfaction with the process of learning and learning achievement. Pekrun and Stephens (2010) pointed out important qualities about instructional design, such as autonomy support and motivational quality of instruction as directly related to emotional design (Plass \& Kaplan, 2016, p. 145). The emotional design in multimedia learning emphasizes motivational and emotional elements through visual appeals, e.g. colours, shapes or anthropomorphic, cartoon-like figures (Mayer \& Estrella, 2014). In general, in learning and teaching environment, emotional design involves thinking about how to stimulate positive moods and emotions in learners.

As mentioned cognitive-affective approaches of learning postulate that motivational factors mediate learning by increasing or decreasing cognitive engagement, but they are still understudied. Thus, there is a lack of investigation of the usage of the multimedia instructional message in an introductory part of the lesson. In this study we investigated the motivational and learning effects of combining two motivational features: teaching in introductory or motivational part of the lesson and using multimedia presentations based on motivational and cognitive principles of the multimedia instructional message.

\section{LITERATURE REVIEW}

\section{Multimedia Learning and Motivation}

Multimedia instructional message combines words, written or spoken, and pictures, static or dynamic, by using multimedia learning principles to promote learning (Mayer 2001). A recognizable shift from cognitive to the affective paradigm in multimedia learning and instructional design is evident in models and theories based on the 
integration of cognitive and affective processes. By explaining both verbal and visual information processing, Mayer (2001) proposed the Cognitive Theory of Multimedia Learning - CTLM. Besides, Moreno's cognitive-affective theory of learning with media - CATLM (Moreno, 2006) extended Mayer's theory of multimedia learning concerning interactive learning, simulations, and virtual reality. Overall, the CATLM adds motivational and emotional aspects to Mayer's multimedia learning principles. Most recently, Plass and Kaplan (2016) developed the Integrated Cognitive Affective Model of Learning with Multimedia (ICALM). The model highlights the importance of emotion and motivation, explaining how cognitive and affective processes are connected and influence one another.

For many years of research, multimedia learning has been focused on developing the multimedia instructional message according to the cognitive design principles and examining the effectiveness of using the multimedia message as a cognitive tool in constructing knowledge (Mayer, 2001, 2014a). New phase has begun in the last ten years by incorporating motivational factors through emotional design in multimedia learning (Um et al, 2012, Mayer \& Estrella, 2014; Mayer, 2014b; Plass et al., 2014; Leutner, 2014; Park, et al., 2014; Heidig et al., 2015; Schneider et al., 2018). By redesigning the relevant graphic object, the emotional design encourages challenge, curiosity, control, and fantasy in multimedia learning. Mayer and Estrella (2014) emphasized an increase in motivation as the reason for implementing emotional design. Uzun \& Yildırım (2018) generally showed an increase in positive emotions if the number of features of the emotional design was increased. Considering PowerPoint as a multimedia tool in education, some studies have shown that insufficiently prepared multimedia presentations can interfere with learning, especially if their purpose was merely to entertain and simplify the content (Levasseur \& Sawyer, 2006; Craig \& Amernic, 2006; Savoy \& Salendy, 2008). On the other hand, using multimedia presentations have enhanced learning and created positive attitudes toward technology and even towards the lecturer (Burke \& James 2008; Berk, 2011; Penciner, 2013; Shigli et al., 2016). Bistrovic (2017) developed the activities and multimedia/traditional teaching aids integrating cognitive and affective elements for teaching in the introductory part of the lesson. Each group of the activities was designed to arouse motivation for learning. The motivation was simulated by stimulating curiosity, exploration, or competition. Multimedia features include sound, text and images, as well as, in the case of presentations, animation, video, and interactivity are included.

\section{Research Goal and Hypotheses}

In the Croatian educational system, teaching the subject of Nature and Society is being conducted in the lower grades of elementary school. The subject aims to introduce students to the world of things and phenomena that surround them, appropriate to their age and psychophysical abilities (De Zan, 2006). Lessons are organized through the following stages: introduction or preparation (motivation), processing new material, practicing, repeating (learning), and checking the effects of the lesson (evaluation). The introductory part at the beginning of each lesson should contribute to the motivation to learn and engage in work during the class. Thus, teachers use motivational techniques to 
intensify learner's motivation during the preparatory part of the lesson. It prepares learners to learn new, or repeat learned content, evokes experiences related to teaching content, and creates the desired atmosphere.

This paper aims to examine whether the use of multimedia in the introductory part of the lesson can have positive effects on the pupils' motivation and learning outcomes in comparison to the traditional design of introductory part of the lesson delivered through verbal interaction between teacher and students.

The three hypotheses were:

H1: Students who are being taught by using a motivational and multimedia instructional message in the introductory part of Nature and Society lesson will have better learning outcomes compared to those who are not being taught using motivational and multimedia instructional messages.

H2: Students who are being taught by using a motivational and multimedia instructional message in the introductory part of Nature and Society lesson will be more motivated to learn as compared to those who are not being taught using motivational and multimedia instructional messages.

H3: Students' positive assessments of the motivational instructional message will be positively correlated with their learning outcome.

\section{METHOD}

\section{Design of the Study}

The field quasi-experiment was conducted in four elementary schools in two counties in Croatia. Initially, ten $4^{\text {th }}$ grade classes were recruited in the study, but since one teacher from the control group of classes withdrew, nine classes participated in the study. The participating classes were assigned in experimental and control groups according to school convenience, not randomly. However, the experimental and the control group were matched by the gender and age of participants. In addition, the two groups equivalence was tested for several other control variables some related to the children (grade for subject Nature and Society in $3^{\text {rd }}$ grade, GPA of the $3^{\text {rd }}$ grade, pre-test of the knowledge in the $4^{\text {th }}$ grade, experience in using computer operationalized as computer screen time per day) and others related to their families (education, working status, marriage status, family income, number of computers in the household). The details are given in the Participants section.

Students in the both groups knew that they participated in the experiment, but they were not familiar with its goals. The independent variable was the experimental treatment with the motivational and instructional message used in the form of multimedia vs in the form of traditional learning materials during introductory part of classes of the subject Nature and Society. The dependent variables were students' learning achievement (operationalized as an achievement in the objective tests and exams of knowledge) and 
motivation to learn (operationalized as students' assessments of instructiveness, interestingness, and fun of the introductory activity on each class).

The treatment in the experimental groups was performed by their regular class teachers. The class teachers in the experimental classes were given multimedia material designed by the author of this research (Bistrovic, 2017) and instructed how to use it. The class teachers in the control groups were provided by the materials for introductory parts of the classes that were comparable by the content and the kind of activity but were presented by using traditional teaching aids and materials. The effort was made to balance objective factors of the multimedia use (time of day, IT equipment) and subjective factors of its use (teacher behaviour, equal instruction to all teachers).

Introductory content and activities (in duration 7-10 minutes) for selected teaching topics were presented in the experimental group using motivational and multimedia instructional messages delivered through Power Point and Prezi presentations. In the control group, the same teaching contents and activities were presented during introductory part of each class but using some of the traditional teaching aids - posters, magnified photographs, printed crossword puzzles, quizzes, story reading, and printed maps.

The introductory activities for the Nature and Society classes consisted of six groups of activities used either as multimedia on computer or in a traditional manner, such as printed text and picture. Six groups of activities were: association games, videos, interactive stories, interactive maps, visual stimuli, and crossword puzzles and quizzes, each of them containing three activities. In the experimental classes, teachers used multimedia during the first 7 to 10 minutes of the lesson to motivate curiosity and learning while in the control classes similar activities were performed but in the traditional printed pictorial or verbal format. The assessment of learning outcomes (knowledge) and motivation of the students were the same for both of the students in experimental and control group and was performed by paper and pencil tests and exams as well as paper and pencil short questionnaires. It is important to stress that multimedia activities were presented in frontal manner for the whole class, and that children did not used individual computers for those activities.

In both control and experimental groups there was no use of multimedia in the central part of the lesson. Thus, except for the introductory part, in the other parts of the lesson, there were the same concerning content and materials in both groups. Immediately after the introductory part of each class, a questionnaire was administered to examine motivational value of the introductory activities used that day. The motivational value of the introductory activity was examined by asking students to assess on 5-point Likert scale how interesting, fun and instructional each activity was. The classroom teachers conducted the teaching, as well as motivation and knowledge examination.

The research was conducted within the school subject of Nature and Society for the 4th grade of elementary school. This subject is taught by elementary school teachers and precedes science and social science subjects in higher classes. The research included the 
two large teaching units of the subject of Nature and Society: Hillside regions of the Republic of Croatia (8 lessons and 1 review lesson), and Mountainous areas of the Republic of Croatia (8 lessons and 1 review lesson). During first 8 lessons and during second 8 lessons three knowledge tests were administered, six altogether. They were supplemented with two knowledge exams after the completion of the two teaching units. Learning outcomes were measured through six more immediate knowledge tests and two global exams. Motivation was measured using students' assessments of each lecture introductory activities i.e. how instructive, interesting and funny they were.

The structure of each teaching class for the treatment and the experimental and control group is presented in Figure 1.

\begin{tabular}{|c|c|}
\hline \multicolumn{2}{|c|}{ Structure of the teaching lessons } \\
\hline Experimental group & Control group \\
\hline Introductory motivational activity & Introductory motivational activity \\
\hline$(7-10$ minutes $)$ & (7-10 minutes) \\
\hline $\begin{array}{l}\text { Motivational activities presented by } \\
\text { multimedia technology through PowerPoint } \\
\text { and Prezi presentations (computer, projector) } \\
\text { in frontal and group manner }\end{array}$ & $\begin{array}{l}\text { Motivational activities presented by teacher } \\
\text { in frontal manner using traditional teaching } \\
\text { aids (paper and pencil, blackboard, posters } \\
\text { etc.) }\end{array}$ \\
\hline $\begin{array}{l}\text { Groups of activities: association games, } \\
\text { videos, interactive stories, interactive maps, } \\
\text { visual stimuli, and crossword puzzles and } \\
\text { quizzes. }\end{array}$ & $\begin{array}{l}\text { Groups of activities: association games, } \\
\text { pictures, stories, maps, photographs, and } \\
\text { crossword puzzles and quizzes. }\end{array}$ \\
\hline Assessment of motivational part of the lesson & Assessment of motivational part of the lesson \\
\hline$(5$ minutes $)$ & (5 minutes) \\
\hline $\begin{array}{l}\text { Activity: questionnaire (educational, } \\
\text { interesting, fun) }\end{array}$ & $\begin{array}{l}\text { Activity: questionnaire (educational, } \\
\text { interesting, fun) }\end{array}$ \\
\hline $\begin{array}{c}\text { Main part of the lesson } \\
\text { (30 minutes) }\end{array}$ & $\begin{array}{c}\text { Main part of the lesson } \\
\text { (30 minutes) }\end{array}$ \\
\hline No multimedia used & No multimedia used \\
\hline
\end{tabular}

Structure of the Learning Classes for Experimental and the Control Group

\section{The Instructional Design of Activities}

For the introductory parts of Nature and Society lessons, six groups of activities were developed: association games, videos, interactive stories, interactive maps, visual stimuli, and, quizzes and crossword puzzles. Each group consisted of three activities, so the same activity group was used three times during the study. In experimental groups, the activities were presented in the form of a multimedia presentation, and in the control groups in traditional forms (printed text and pictures).

Associations games. Association games have been often used as a motivational technique since they stimulate curiosity. For the experimental group, the games were made with Microsoft PowerPoint, and for the control group using paper posters. In multimedia mode, students were discovering fields and guessing the solution together looking at the PPT presentation. In traditional mode, they watched a paper poster on which the table was covered with cardboard papers. After discovering the partial 
solutions, they offered the final solution, thus introducing the new lesson. The contents of the associations were the same in both groups.

Videos. The video is often used as an educational aid for stimulating interest and motivation in students. By watching the videos, students listened to music and view photographs specific to particular geographical areas of the Republic of Croatia. The videos used in the experiment were made with Windows Movie Maker and embedded in presentations with the Prezi online tool. Images embedded in the video of the experimental group were printed and shown to the students of the control group with the same background music as it was in the video for the experimental group.

Interactive Stories. Interactive stories hold the student's attention because they require their feedback or active participation. By listening to and participating in interactive stories, students reviewed previously acquired knowledge by choosing the course of the story. The interactive stories for the experimental group were made with Microsoft PowerPoint, and for the control group were written on paper with additional notes and markings where students are expected to interact. In both groups, the content of the interactive stories and the accompanying tasks were the same for both groups.

Interactive Maps. Interactive maps are inherently the significant activity group for teaching the subject of Nature and Society. Students listened to the recorded voice of the animator, selected cards, placed city names next to labels, and indicated settlements on the map. Two activities in the interactive map group were created with Prezi and the one by PowerPoint. There were three types of interactive maps. The first type consisted of a blind map with six dots marked. The task for the students was to determine the names of the places hiding behind the dots. Students in the control group were given blind maps with dots printed on paper, and they inscribed the names of settlements next to the dots. The second activity is designed using the animator. Students from both groups had on their benches printed small maps of the Republic of Croatia with marked larger cities and counties. Through presentation, the students of the experimental group listened to the recorded voice of the animator - a boy named Marko, who told them which way he traveled on his trip. The students followed Markov's way in the maps. In the end, a map with a precisely drawn path appears as feedback. The students in the control group did not listen to the voice from the presentation, but their teacher. In the end, the teacher showed them the exact path on an enlarged, printed map that looks the same as their reduced size. The third activity of interactive maps was shaped in the form of a map of the Republic of Croatia in the class. The slide of the presentation contained cards, marked with letters. Selecting the letter opened the name of a settlement, lake, river or mountain. The teacher checked the answer, and the flag was "placed" on the map in the place that the students were supposed to show on the class map. The students in the control group chose the names of the settlements, lakes, rivers, and mountains on paper cards and also received feedback from the teacher.

Visual Stimuli. Visual stimuli, in the form of photo descriptions, photo discovery, and memorizing of visual representations were used to encourage the use of visual perception and visual thinking. By using visual stimuli, students defined and described settlements, recalling their experiences. Two activities in the visual stimulation group 
were created with the Prezi, and one with PowerPoint. There were three types of activities. The first activity consisted of describing photographs of rural settlements on presentation and presenting learners' observations and experiences. The control group had the same task, with the same, printed and enlarged photographs. The second activity was based on careful observation of the presented concepts and memorization. Teachers showed the pictorial representations to the students, and they reproduced and analysed what they saw. The control group followed the same shown on the cards. The third visual stimuli activity was discovering and describing a hidden photo. After the whole photo was revealed, students described it. Students in the control group had the same task. The same photo was enlarged, printed and covered with cards.

Quizzes and Crossword Puzzles. Crossword puzzles and quizzes are often used motivational techniques. Through crossword puzzles, students come up with solutions that indicate some familiar or new concepts based on their existing knowledge. Quizzes, in which different forms of work can be combined, encourage students to collaborate, speed, attention and significantly stimulate motivation because they resemble play. Using quizzes and crossword puzzles, students identified the highlighted settlements, answered questions, named, defined, described and linked with previously learned content. The quiz and crossword activity group contained one quiz made in Microsoft PowerPoint and two crosswords made in Prezi. The content of quizzes and crossword puzzles was the same in both research groups.

\section{Procedure}

The study was field experiment which was performed during the regular school year (September to June) and regular classes of the Nature and Society subject. There were four main parts of the study (Figure 2). In the first stage (September), the recruitment of the participating schools, teachers, and students was completed, and parental consent was acquired. In that stage, all participating students' knowledge of the subject Nature and Society from the previous, 3rd class was tested. The children also gave data on their computer experiences as well as on their marks from Nature and Society in 3rd grade as well as about 3rd grade GPA. The student's parents filled in questionnaires concerning their socioeconomic status and children's daily screen-time on computers. Finally, teachers from both groups were instructed on how to use multimedia and traditional materials in the introductory part of each lesson.

In the second part that lasted 16 weeks, students attended regular classes of Nature and Society. In the experimental classes, teachers used multimedia during introductory part of the lesson while in the control classes similar activities were performed but in the traditional printed pictorial or verbal format. However, in both the experimental and the control classes, children assessed how interesting, fun and instructive was the motivational activity used in the introductory part of the lesson. Also, after $3^{\text {rd }}, 6^{\text {th }}, 9^{\text {th }}$, $11^{\text {th }}, 14^{\text {th }}$, and $15^{\text {th }}$ lessons, short knowledge tests were completed by students in both the experimental and the control classes. 
The third part consisted of the written exams of the knowledge that were performed after eight instructional and one review lesson in the first and eight instructional and one review lesson of the second teaching unit.

\section{Instruments}

Different assessment instruments were constructed to collect data on students and their parents and evaluate the effectiveness of motivational and multimedia instructional messages.

Questionnaire for parents. This questionnaire consisted of 12 items about education, age, marital and working status of the parents, family structure, and number of computers in the household and child's daily computer screen time. The data from this questionnaire was used to compare the experimental and control group for several controlling variables and is presented in the section on Participants.

Questionnaire for students. The data on students' habits and experiences with computers and their screen time, as well as their GPA from $3^{\text {rd }}$ grade and their marks from the subject Nature and Science in the $3^{\text {rd }}$ grade was examined by 13 items questionnaire.

Knowledge tests and exams. Pre-test of the knowledge of the material of Nature and Society from the $3^{\text {rd }}$ grade consisted of 10 questions and was designed by the school teacher and the author of this study. Six short tests of knowledge consisting of 5 questions each were constructed for the assessment of knowledge acquired after several lessons. Although having the same number of questions the tests were scored differently (1st - 19 points, 2 nd -14 points, 3 rd -19 points, $4^{\text {th }}-17$ points, 5 . -12 points, $6 .-28$ points). The tests consisted of tasks of completion, alternative tasks - tasks with "yes" and "no" statements, multiple-choice tasks, sorting and matching.

The two additional knowledge exams were constructed to determine the effectiveness of using motivational and multimedia instructional messages in acquiring new knowledge after each learning unit. The first knowledge exam had 17 questions (43 points) and the second 15 questions (19 points).

Questionnaires for the assessment of motivational aspects of introductory activities. After each lesson, the introductory activities were assessed on the three 5-point Likert a scale, indicating how interesting, fun and instructional, was particular introductory activity. The scale used was in concordance to Croatian school marks where1 mean insufficient, 2 sufficient, 3 good, 4 very good and 5 excellent. These questionnaires were intended to examine the degree of interest and attention in students regarding the particular introductory activity. During the study, 16 questionnaires (1 questionnaire per school hour) were conducted to examine the student's motivation for learning.

\section{Participants}

The participants were students from four different primary schools in two Croatian counties and nine classrooms. The sample consisted of 170 4th grade students. 
Participants were divided into the experimental and control group regarding the number of students in the class, a previous average class grade for the subject of Nature and Society and the average class grade for all subjects, a pre-test score (in the subject of Nature and Society in $3^{\text {rd }}$ grade), and learners experience with the computer. The experimental group consisted of 97 participants and the control group of 73 participants. The final number of participants in the two groups was not identical due to the dropout of one teacher participation and consequently, her whole class. More detailed data on the experimental and control groups and control variables are presented in Table 1. There were a similar number of boys and girls in the two groups $(\chi 2=.004$, n.s.).

There was no significant difference in the mean grades of the students in the experimental and the control group for the subject Nature and Society in the $3^{\text {rd }}$ grade $(t$ $=0.218, \mathrm{p}=0.834)$ nor in the student's grade point average (GPA) for the third grade $(t$ $=0.516, p=0.622$ ). Comparing the results of the pre-test of knowledge of Nature and Society from $3^{\text {rd }}$ grade between the students of the experimental and the control group by t-test, it was found that the two groups did not differ significantly in their preknowledge assessed in the $4^{\text {th }}$ grade $(t=0,393, p=0,69)$.

Table 1

Participants in the Experimental $(\mathrm{N}=97)$ and Control $(\mathrm{N}=73)$ Group and Their Average $\underline{\text { Marks in Subject Nature and Science and GPA in } 3^{\text {rd }} \text { Grade and the Knowledge Pre-test }}$

\begin{tabular}{|c|c|c|c|c|c|c|}
\hline Group & $\begin{array}{l}\text { Total } \\
\mathrm{N}\end{array}$ & $\begin{array}{l}\text { Boys } \\
\text { N (\%) }\end{array}$ & $\begin{array}{l}\text { Girls } \\
\mathrm{N}(\%)\end{array}$ & $\begin{array}{l}\text { GPA in } 3^{\text {rd }} \\
\text { grade } \\
M(S D)\end{array}$ & $\begin{array}{l}3^{\text {rd }} \text {-grade } \\
\text { mark } \\
M(S D)\end{array}$ & $\begin{array}{l}\text { Pre-test exam } \\
\text { score } \\
\text { M (SD) }\end{array}$ \\
\hline Experimental & 97 & $\begin{array}{l}50 \\
(51.5)\end{array}$ & $\begin{array}{l}47 \\
(48.4 \%)\end{array}$ & $\begin{array}{l}4.66 \\
(0,13)\end{array}$ & $\begin{array}{l}4.41 \\
(0.26)\end{array}$ & $\begin{array}{l}6.87 \\
(1.71)\end{array}$ \\
\hline Control & 73 & $\begin{array}{l}38 \\
(52.0)\end{array}$ & $\begin{array}{l}35 \\
(47.9 \%)\end{array}$ & $\begin{array}{l}4.59 \\
(0.28)\end{array}$ & $\begin{array}{l}4.36 \\
(0.43)\end{array}$ & $\begin{array}{l}6.77 \\
(1.57)\end{array}$ \\
\hline
\end{tabular}

Legend: GPA and subject grades in Croatia vary from 1- insufficient to 5 - excellent.

The two groups were compared for two ICT related variables from parent and child questionnaires. According to parental reports most of the students in the two groups spent daily 1 to 3 hours on computer but they did not differ in daily screen time (EG = $\left.85.7 \%, \mathrm{CG}=81.1 \%, \chi^{2}(2,170)=3.380, p<.001\right)$. In the both groups most of the children have their own computer $(\mathrm{EG}=59.8 \%, \mathrm{CG}=66.7 \%, \chi 2(1,170)=0.814, p=$ $.367)$ as well as their own mobile phone $\left(\mathrm{EG}=68 \%, \mathrm{CG}=75.4 \%, \chi^{2}(2,170)=1.05, p\right.$ $=.305$ ). It can be concluded that both groups of children are similarly familiar with the use of computers and smartphones.

The groups were equivalent according several parental and family variables as well. Most of mothers and fathers of children in the both experimental and control group were in the age group of 36 to 40 years old $\left(\mathrm{EG}_{\text {Mothers }}=34.8 \%, \mathrm{CG}_{\text {Mothers }}=35.2 \%, \chi 2(3,170)\right.$ $\left.=0.232, p=.972 ; \mathrm{EG}_{\mathrm{Fathers}}=41.3 \%, \mathrm{CG}_{\mathrm{Fathers}}=47.9 \%, \chi 2(3,170)=0.492, p=0.921\right)$. The groups didn't differ in working status of neither mothers $\left(\mathrm{EG}_{\text {Mothers }}=75 \%, \mathrm{CG}_{\text {Mothers }}\right.$ $=74.6 \%, \chi 2(2,170)=0.087, p=.958)$ nor fathers $\left(\mathrm{EG}_{\mathrm{Fathers}}=79.3 \%, \mathrm{CG}_{\mathrm{Fathers}}=78.9 \%\right.$, $\chi 2(2,170)=0.482, p=, 786)$. Educational level of most mothers and fathers in the both groups is secondary school $\left(\mathrm{EG}_{\text {Mothers }}=59.8 \%, \mathrm{CG}_{\text {Mothers }}=57.7 \%, \chi 2(2,170)=0.439, p\right.$ 
$\left.=.803 ; \mathrm{EG}_{\text {Fathers }}=66.3 \%, \mathrm{CG}_{\text {Fathers }}=70.4 \%, \chi 2(2,170)=1.153, p=.562\right)$. The experimental and the control groups were similar according to marital status of their parents and most of them were married $\left(\mathrm{EG}=78,9 \%, \mathrm{CG}=81.2 \% ; \chi^{2}(1,170)=5.649, p\right.$ $=.227)$. Finally, the groups of children came from the families of middle-income category $\left(\mathrm{EG}=46,2 \%, \mathrm{CG}=63,2 \% ;\left(\chi^{2}(1,170)=4.870, p=.088\right)\right.$.

\section{FINDINGS}

\section{Instructional Outcomes}

The first hypothesis states that students who are being taught by using a motivational and multimedia instructional message in the introductory part of Nature and Society lesson will have better learning outcomes compared to those who are being taught using traditional teaching materials. To test the hypothesis, we compared the two groups regarding the results obtained for the three short tests during the first part of the research, and the results obtained for three short tests, during the second part of the research, as well as the results of two knowledge exams (Table 2).

Although the distributions of the variables were not normal, they were all negatively skewed, indicating that the tests and exams were probably not difficult enough. The ttest for independent groups revealed a significant difference between groups regarding the second and the third test of the first part of the experiment. In those two short tests (study unit the Hills of the Republic of Croatia, conducted in the first semester), the students of the experimental group achieved significantly better results compared to the students of the control group. The experimental group which learned with the aid of multimedia also achieved significantly better results on the first knowledge exam than the control group of students (Table 2).

Out of all three short exams of the second part of the experiment (the study unit Mountainous Areas of the Republic of Croatia, conducted in the second semester), the students of the experimental group achieved significantly better results on the third test. Also, there was no statistically significant difference between the experimental and control group of students on the second exam (Table 2).

Table 2

Results of Comparison of Experimental (N=97) and Control Group (N=73) Achievement in Six Short Tests and Two Exams of the School Subject Nature and Society

\begin{tabular}{|c|c|c|c|c|c|c|}
\hline & \multicolumn{3}{|c|}{ Experimental group } & \multicolumn{3}{|l|}{ Control group } \\
\hline & $M$ & $S D$ & $M$ & $S D$ & $t$ & $p$ \\
\hline Test 1.1 & 13.71 & 3.410 & 12.87 & 3.069 & 1.623 & .107 \\
\hline Test 1.2 & 11.92 & 1.988 & 10.88 & 2.472 & 2.821 & .006 \\
\hline Test 1.3 & 15.79 & 3.586 & 12.71 & 4.337 & 4.940 & .001 \\
\hline Exam 1 & 37.33 & 5.401 & 34.60 & 6.560 & 2.902 & .001 \\
\hline Test 2.1 & 13.79 & 2.637 & 13.38 & 2.991 & 0.921 & .358 \\
\hline Test 2.2 & 9.87 & 2.100 & 9.25 & 2.346 & 1.738 & .084 \\
\hline Test 2.3 & 24.96 & 3.762 & 23.00 & 5.072 & 2.658 & .009 \\
\hline Exam 2 & 15.37 & 2.977 & 15.93 & 2.992 & 1.195 & .232 \\
\hline
\end{tabular}




\section{Motivational Outcomes}

To test the second hypothesis which stated that students who are being taught by using a motivational and multimedia instructional message in the introductory part of Nature and Society lesson will be more motivated to learn as compared to those who are not being taught using motivational and multimedia instructional messages we did analysis of students' assessments of each lecture introductory activities i.e. how instructive, interesting and funny they were (assessments on the scale 1-5). For that reason, we calculated sums of assessments for each of the three features for all the activities used in the lectures in first and the second part of the study (Table 3). Then we compared experimental and control group assessments of the activities by t-test. The results indicate that students whose teachers used instructive media in the introductory part of the lecture found those activities more instructive, more interesting and more fun than students whose teachers used traditional materials (Table 3).

Table 3

Average Assessments of Features of Introductory Instructional and Multimedia Designs of Students in Experimental (N=97) and Control Group $(\mathrm{N}=73)$ in Two Parts of the Research

\begin{tabular}{llcccc}
\hline Feature of the design & Group & $M$ & $S D$ & $t$ & $p$ \\
\hline Instructive 1 & Experimental & 4.29 & .238 & \multirow{2}{*}{3.99} & \multirow{2}{*}{.001} \\
& Control & 3.89 & .841 & & \\
Interesting 1 & Experimental & 4.23 & .280 & 3.92 & .001 \\
\multirow{2}{*}{ Fun 1 } & Control & 3.82 & .880 & & \\
& Experimental & 4.14 & .363 & 2.96 & .004 \\
\hline \multirow{2}{*}{ Instructive 2 } & Control & 3.82 & .879 & & \\
\multirow{2}{*}{ Interesting 2 } & Experimental & 4.81 & .321 & \multirow{2}{*}{4.70} & \multirow{2}{*}{.001} \\
& Control & 4.35 & .892 & & \multirow{2}{*}{ Fun 2 } \\
& Experimental & 4.84 & .281 & 5.44 & .001 \\
& Control & 4.28 & .954 & & \multirow{2}{*}{.001} \\
\hline
\end{tabular}

We also compared different aspects of the instructional designs within the experimental and control group by the paired t-tests in order to see which feature of multimedia and traditional introductory activities delivered by instructional aids was rated the highest. For that reason, we calculated average assessments from two parts of the study for all features for each of the group. Students in the experimental group assessed that the activities were similarly instructive $(M=4.59, S D=.272)$ and interesting $(M=4.58, S D$ $=.279, t=0.665, p=.507)$, but significantly less fun than instructive and interesting $(M$ $=4.22, S D=.327, t=3.55, p<.001 ; t=3.18, p<.002)$.

On the other hand, students in the control group assessed all the aspects of the traditionally given activities similarly $(M=4.18, S D=.835 ; M=4.10, S D=.877 ; M=$ $4.08, S D=.902$ ). They also rated them as very instructional, interesting and funny. $\mathrm{T}$ test showed that there were no statistically significant differences among assessments of different features of the traditional interactive activities (instructive vs interesting $t=$ 
1.93, $p<.058$; instructive vs fun $t=1.36, p<.178$; interesting vs fun, $t=.047, p<$ $.963)$.

However, the assessments of all the multimedia introductory activities were quite high and indicated that the activities were more than very instructional, very interesting and very funny.

The comparison of the experimental and control group of the total assessments (average of interesting, instructional and fun) for each kind of six introductory activities indicated that all activities were rated better when they were in multimedia format except for quizzes $(M=4.68, S D=.608$ vs $M=4.58, S D=.847, t=1.53, p=.126)$ and picture descriptions $(M=4.47, S D=.805$ vs $M=4.23, S D=1.19, t=.951, p=.343)$.

\section{Relationship between Motivational Assessments and Learning Outcomes}

The last hypothesis that was tested stated that more positively assessed emotional and motivational introductory activities will be related to better learning outcomes irrespective of media used for their delivery. Therefore, we calculated Pearson's correlations between students' assessments of introductory activities and their results on tests and exams of knowledge (Table 4).

Table 4

Correlation between Students' Assessments of Features of Introductory Activities and Learning Attainment Measured by Tests and Exams ( $\mathrm{N}=172)$

\begin{tabular}{llll}
\hline & \multicolumn{3}{c}{ Assessment of the introductory activities } \\
\cline { 2 - 4 } Test/exam result & Instructive & Interesting & Fun \\
\hline Test 1.1. & .15 & $.17^{*}$ & $.18^{*}$ \\
Test 1.2 & $.30^{* *}$ & $.29^{* *}$ & $.22^{* *}$ \\
Test 1.3. & $.20^{*}$ & $.22^{*}$ & $.20^{*}$ \\
\hline Exam 1 & .06 & .03 & .04 \\
\hline Test 2.1. & $.16^{* *}$ & .15 & $.18^{*}$ \\
Test 2.2. & $.19^{* *}$ & $.22^{* *}$ & $.24^{* *}$ \\
Test 2.3 & $.20^{* *}$ & $.35^{* *}$ & $.36^{* *}$ \\
\hline Exam 2 & .10 & .11 & .10 \\
\hline Legend: ${ }^{*} p<.05,^{* *} p<.01$ & &
\end{tabular}

The correlations between students' assessments of the emotional and motivational aspects of introductory activities irrespective of their mode of delivery were positive and mainly statistically significant but rather low. They indicate that the more the students found activities interesting, instructive and funny, the better test results they had. However, the positive effects were related to the tests that were closer in time to the activities, while there was no significant relationship with the more distant exams' results. In addition, probably there were no correlation of knowledge and motivational aspects of instructional messages because children learned for the test irrespective of the type of instruction but because they are interested in the topic or they want to get good marks. 


\section{DISCUSSION}

This research was conducted under natural conditions in school and during regular classes. To the greatest possible extent, both objective factors (e.g. working conditions, working materials, IT equipment) and subjective factors (e.g. teacher behaviour, equal instruction to all teachers) were harmonized. As an advantage of natural conditions, students were learning in their usual settings, and with a well-established and wellknown routine. The first hypothesis of the study was partially confirmed - students who have been taught by a motivational and multimedia instructive message in the introductory part of Nature and society lesson had better learning results in more immediate tests. However, that effect was partially visible in the more global exams. Our second hypothesis was confirmed. Students who have been thought by a motivational and multimedia instructive message in the introductory part of Nature and society lesson found those messages more instructive, more exciting and funnier compared to those who have not been taught with the motivational and multimedia instructive message. Traditional learning aids in the introductory part of the lessons were rated similarly interesting, instructive and funny, while multimedia presentations were assessed as more interesting and instructive than funny.

Although the later may seem unexpected, the activities were designed to stimulate learning and not playing. . Since in both groups the frontal mode of teaching was used, it is possible that activities on the computer would be more interesting if they were presented on the computer individually to each student. Out of the six groups of activities, four (association games, videos, interactive stories, and interactive maps) were rated as more interesting, instructive and funny when presented in multimedia than traditional format. Quizzes and crossword puzzles, and visual stimuli, on the other hand, were rated equally irrespective of the format in which they were presented. Those findings may have practical implications for teachers when they prepare teaching materials for the introductory parts of the lessons. Finally, the third hypothesis concerning the positive relationship of introductory motivational activities with children's learning outcomes was confirmed. However, the positive effect was not related to multimedia but introductory activities generally. The positive correlation between learning outcomes and motivational aspects of instructional messages were found in more immediate tests (after several lessons) but not in final exams (after each of the learning unit). Probably, children learned for the exams irrespective of the type of instruction but because they were interested in the topic or they wanted to get good marks.

The effectiveness of multimedia in teaching, to a large extent, depends on the teaching style of the teacher (Brock \& Joglekar, 2011), and the right question is how and when to use multimedia presentation (Jordan \& Papp, 2013). Each teacher must understand the capabilities of the tool itself (must be systematically upgraded and enriched) and its contribution to the learning scenario and the achievement of educational goals. Some studies have shown that multimedia presentations have not affected learning outcomes or motivation (Susskind, 2005) or even negatively affected students' performance (Khoury \& Mattar, 2012), or that the purpose was merely to entertain and simplify the 
content (Levasseur \& Sawyer, 2006; Craig \& Amernic, 2006; Savoy \& Salendy, 2008). Conversely, some studies have shown that using multimedia presentations enhances learning and also creates positive attitudes toward technology or the lecturer (Burke \& James 2008; Berk, 2011; Penciner, 2013, Shigli et al., 2016; Hadiyanti \& Widya, 2018).

However, the principles of motivational design are valid and stable over the years (Keller, 2008). In line with this, the results obtained have shown the positive impact of motivational and multimedia instructional messages on student motivation. Further, the students who have been taught by a motivational and multimedia instructive message during the introductory part of the lesson had better learning achievements although that effect was smaller in the second part of the research. The differences concerning better results of short exams compared to knowledge test could be interpreted as an influence of multimedia and instructional messages on short-term memory, while students still have to make an individual effort to gain knowledge. The results obtained are also in line with multimedia learning and emphasizes an increase in motivation as the reason for considering both the emotional design and cognitive principles of multimedia learning (Mayer \& Estrela, 2014, Plas \& Kaplan, 2016, Mayer, 2017).

Future research on motivational instructional multimedia could be directed on investigating the motivational and multimedia message in other subjects or teaching areas where teachers notice reduced student interest.

\section{CONCLUSION}

The model of the motivational and multimedia instructional message, consisting of six activity groups (associations, quizzes, and crosswords, video, interactive stories, interactive maps, and visual stimuli) showed as suitable for use in teaching the subject of Nature and Society. Applying the model refreshed the teaching process and made it attractive to students. The results of the study provided scientific insights into motivational multimedia and instructive message that considers both multimedia and motivational aspects of teaching and learning. The practical contribution of the research is the possible application of the developed teaching materials based on motivational multimedia in the educational process. Overall, the students learned better and showed more interest and positive reactions compared to those who learned without multimedia instructional messages. However, our study showed that the use of multimedia motivational activities even in one part of the lesson (introductory) may improve shortterm learning outcomes, but that the effect is not necessarily durable. By blending motivational and multimedia aspects, this research has given new insight into the effects of multimedia on student motivation and knowledge acquisition. Future research should be more focused on academic achievement effects of the specific activities for which motivational and multimedia instructional message is created 


\section{ACKNOWLEDGMENTS}

The authors thank participating schools, teachers, students and their parents.

\section{REFERENCES}

Berk, R. A. (2011). Research on PowerPoint ${ }^{\circledR}$ : From basic features to multimedia. International Journal of Technology in Teaching and Learning, 7(1), 24-35.

Bistrovic, J. (2017). Development and testing the model of the motivational and multimedia instructional message (Unpublished doctoral dissertation). Faculty of Humanities and Social Sciences, University of Zagreb, Croatia.

Burke, L. A., \& James, K. E. (2008). PowerPoint-based lectures in business education: An empirical investigation of student-perceived novelty and effectiveness. Business Communication Quarterly, 71(3), 278-296.

De Zan, I. (2006). Methodology of the subject science and society. Zagreb: SK.

Heidig, S., Müller, J., \& Reichelt, M. (2015). Emotional design in multimedia learning: Differentiation on relevant design features and their effects on emotions and learning. Computers in Human Behavior, 44(81), 81-95. doi: 10.1016/j.chb.2014.11.009.

Hadiyanti, K. M., \& Widya, W. (2018). Analyzing the values and effects of PowerPoint presentations. LLT Journal: A Journal on Language and Language Teaching, 21. doi:10.24071/llt.2018.Supp12108.

Jordan, L. A., \& Papp, R. (2013). PowerPoint: It's is not: YES or NO - It's when and how. Research in Higher Educational Journal, 22, 307 - 319.

Keller, J. M. (1987). Development and use of the ARCS model of motivational design. Journal of Instructional Development, 10(3), 2-10.

Keller, J. M. (2008). First principles of motivation to learn and e3 learning. Distance Education, 29(2), 175-185.

Khoury, R. M., \& Mattar, D. M. (2012). PowerPoint in accounting classrooms: Constructive or destructive? Int Journal of Business and Social Science, 3(10), 240-259.

Leutner, D. (2014). Motivation and emotion as mediators in multimedia learning. Learning and Instruction, 29, 174-175. doi:10.1016/j.learninstruc.2013.05.004.

Mayer, R. (2001). Multimedia Learning. Cambridge: Cambridge University Press. doi: $10.1017 / \mathrm{CBO} 9780511811678$

Mayer, R. (Ed.). (2014a). The Cambridge handbook of multimedia learning (Cambridge Handbooks in Psychology). Cambridge: Cambridge University Press. doi: 10.1017/CBO9781139547369. 
Mayer, R. E. (2014b). Incorporating motivation into multimedia learning. Learning and Instruction, 29, 171-173. doi:10.1016/ j.learninstruc.2013.04.003.

Mayer, R. E. (2017). Using multimedia for e-learning. Journal of Computer Assisted Learning, 33(5). doi: 10.1111/jcal.12197.

Mayer, R. E., \& Estrella, G. (2014). Benefits of emotional design in multimedia instruction. Lear and Instruction. 33(1), 12-18. doi: 10.1016/j.learninstruc.2014.02.004.

Malone, T. W., \& Lepper, M. R. (1987). Making learning fun. A taxonomy of intrinsic motivations for learning. Aptitude, learning, and instruction, 3, 223-253.

Moreno, R. (2006). Does the modality principle hold for different media? A test of the method-affects-learning hypothesis. J of Computer Assisted Learning, 22(3), 149-158.

Penciner, R. (2013). Does PowerPoint enhances learning? Canadian Journal of Emergency Medicine (CJEM), 15(2), 109-112. doi: 10.2310/8000.2013.130756.

Pekrun, R., \& Stephens, E. J. (2010). Achievement emotions: A control-value approach. Social and Personality Psychology Compass, 4(4), 238-255.

Park, B., Plass, J., \& Brünken, R. (2014). Cognitive and affective processes in multimedia learning. Learning and Instruction, 29, 125-127. doi: 10.1016/j.learninstruc.2013.05.005.

Plass, J. L., \& Kaplan L. (2016). Emotional design in digital media for learning. In S. Tettegah, \& M. Gartmeier (Eds.), Emotions, technology, design, and learning (pp.131161). New York, NY: Elsevier. doi: 101016/B978-0-12-801856-9.00007-4.

Savoy, A., Proctor, R. W., \& Salendy, G. (2008). Information retention from PowerPoint and traditional lectures. Computers \& Education, 52(4), 858-867.

Susskind, J. E. (2005). PowerPoint's power in the classroom: enhancing students' selfefficacy and attitudes. Computers \& Education, 45(2), 203-215. doi: 10.1016/j.compedu.2004.07.005.

Schneider, S., Nebel, S., Beege, M., \& Rey, G. D. (2018). Anthropomorphism in decorative pictures: Benefit or harm for learning? Journal of Educational Psychology, 110(2), 218-232. doi: 10.1037/edu0000207.

Shigli, K., Agrawal, N., Nair, C., Sajjan, S., Kakodkar, P., \& Hebbal, M. (2016). Use of PowerPoint presentation as a teaching tool for undergraduate students in the subject of gerodontology. Journal of Indian Prosthodontic Society, 16(2), 187-192. doi: 10.4103/0972-4052.167940.

Uzun, A. M., \& Yıldirım, Z. (2018). Exploring the effect of using different levels of emotional design features in multimedia science learning. Computers \& Education, 119, 112-128. doi: 10.1016/j.compedu.2018.01.002. 
Um, E. R., Plass, J. L., Hayward, E. O., \& Homer, B. D. (2011). Emotional design in multimedia learning. J of Edu Psychology, 104(2), 485-498. doi: 10.1037/a0026609. 